\title{
Chapter 7 \\ Introduction to the Section: \\ On the Manifestations and Consequences of Ageism
}

\author{
Liat Ayalon and Clemens Tesch-Römer
}

The chapters in this section describe in detail the manifestations and consequences of ageism. The diversity of settings and situations described in this section clearly indicates the pervasiveness of the phenomenon. Ageism occurs at the individual level as well as at the societal/structural level, and the interaction between these two levels further perpetuates its occurrence. The negative impact of ageism on the lives of older adults is clearly discussed and demonstrated in the ten chapters presented in this section.

The first chapter in this section, by Kydd, Fleming, Gardner, and HaffordLetchfield (2018; Chap. 8) critically examines ageism in the third age that is directed towards individuals in their fourth age. This chapter follows the definition of ageism as the "enemy within" (Levy 2001) by discussing ways in which older adults attempt to disassociate themselves from old age and decline. This division between the third and the fourth age is clearly articulated by the author John Burroughs (1837-1921): "To me, old age is always ten years older than I am". In the successful or active ageing models, the third age is associated with good health and a high degree of societal participation, whereas the fourth age represents the failure to maintain the functioning of middle age and the surrender into decline and decay. Hence, the fourth age is classified as "old," whereas the third age makes attempts to stay "forever young."

The second chapter in this section, by Shiovitz-Ezra, Shemesh, and McDonnellNaughton (2018; Chap. 9) corresponds to the chapter by Kydd et al. (2018; Chap. 8) by articulating the negative consequences of ageism on older adults' satis-

\footnotetext{
L. Ayalon $(\bowtie)$

Louis and Gabi Weisfeld School of Social Work, Bar Ilan University,

Ramat Gan 52900, Israel

e-mail: liat.ayalon@biu.ac.il

C. Tesch-Römer $(\square)$

German Centre of Gerontology, Berlin, Germany

e-mail: clemens.tesch-roemer@dza.de

L. Ayalon, C. Tesch-Römer (eds.), Contemporary Perspectives on Ageism, International Perspectives on Aging 19, https://doi.org/10.1007/978-3-319-73820-8_7
} 
faction with social life, manifested in high levels of loneliness. In the case of older adults, ageism likely plays a role as an intra-psychic experience that inhibits older adults from developing relationships with other older adults (similar to the case described by Kydd et al. 2018) as well as with people of different age groups. Ageism also serves as a structural barrier in societies that divide young and old, allowing for very little contact between people of different generations. Finally, although loneliness is in part a subjective experience associated with dissatisfaction with one's relationships, it is important to acknowledge that many objective losses in old age also make older adults particularly vulnerable to loneliness. These vulnerabilities are further intensified by the experience of ageism.

Another area where ageism plays a role is sexuality. At the micro-level, the perceptions and beliefs of older adults impact their expectations as well as behaviours regarding sexuality. However, older adults do not operate in isolation. Instead, their experiences, expectations, and behaviours are largely influenced by messages portrayed in the media, and by health care professionals, long-term care providers, and family members, among others. The chapter by Gewirtz-Meydan, HaffordLetchfield, Benyamini, Phelan, Jackson, and Ayalon (2018; Chap. 10) points to the role of ageism in shaping the discourse about sexuality in old age. The view of sexuality as non-existent and invisible in old age, or as a purely bio-medical "problem," serves to deprive older adults of their sexuality and does not allow for the actual diversity of experiences, desires, and beliefs about sexuality among older adults.

The media as a way to portray and also influence reality is discussed in the chapter by Loos and Ivan in this section (2018; Chap. 11). The chapter demonstrates how the visual presentation of older adults has changed over the years. Whereas early representations of older adults were minimal and tended to focus on the negative, current representations of older adults follow the spirit of successful and active ageing. Although the latter perspectives represent an attempt to move away from the pathology of old age and ageing, they clearly place on older adults the responsibility for their own decline and eventual mortality and, thus, they can be seen as promoting another form of ageism (Liang and Luo 2012). The unreasonable expectations disseminated by the media likely reinforce ageism and may increase social isolation and loneliness among older adults who "fail" to age successfully (e.g., the fourth age in Kydd's chapter (2018; Chap. 8)).

In this section, Dolberg, Sigurðardóttir, and Trummer (2018; Chap. 12) discuss an unexplored yet highly topical issue that has made the headlines recently, namely, immigrants and immigration policies. Although ageism is not the first topic that comes to mind when considering immigration, there is no doubt, after reading this chapter, that ageism plays a substantial role in the life of older immigrants. As illustrated in the chapter, older immigrants are exposed to double or even triple jeopardy by policies that privilege younger immigrants and by cumulative stresses and disadvantages associated with the deleterious effects of immigration status and old age combined.

The chapter by Wyman, Shiovitz-Ezra, and Bengel (2018; Chap. 13) on ageism in the health care system and the chapter by Fialová, Leppee, Kummer, and Držaić (2018; Chap. 14) on ageism and medication in older adults are highly important 
given the fact that older adults have to rely on adequate health care services and are at a high risk for taking a large number of medications. This reliance on medical services in later life has even led some philosophers to ask whether older adults have a duty to die (Hardwig 1997). The chapter by Wyman, Shiovitz-Ezra, and Bengel (2018) provides a comprehensive overview of the role of ageism in the health care system by demonstrating how ageism operates at the individual level, at the mesolevel, and at the macro-level to impact the quality of health care provided to older adults. This chapter is complemented by the chapter on ageism and medication use, which outlines the negative consequences of ageism on the prescription of medication for older adults. This chapter also contains recommendations for strategies to reduce inappropriate prescribing, risky polypharmacy, and medication non-adherence in older patients.

Bodner, Palgi, and Wyman (2018; Chap. 15) offer a fresh perspective on ageism in mental health care. They vividly illustrate how both the assessment and the treatment of mental illness are impacted by ageism. The role of countertransference has received substantial attention in the mental health literature, but, in this chapter, it is viewed in the context of ageism, as the psychologist's feelings and attitudes about age. Given the stigma of old age, many symptoms of mental illness are seen as signs of ageing and vice versa. This often hampers the quality of treatment provided to older adults with mental illness.

Like mental illness, dementia is a highly stigmatized condition. Hence, the chapter by Evans in this section (2018; Chap. 16) explores the role of double stigma in the life of older adults who suffer from dementia, and describes how this double stigma impacts the care provided to them. Evans illustrates how older adults and having dementia become synonymous at times. In addition to other chapters in this section (Wyman, Shiovitz-Ezra, and Bengel 2018; Fialová et al. 2018; Bodner et al. 2018; and Ben-David, Malkin, and Erel 2018), this chapter stresses the pervasive and debilitating presence of ageism in the health care system. Clearly, ageism impacts older adults' access to health care services, as well as the quality and availability of services.

The concluding chapter in this section is by Ben-David et al. (2018; Chap. 17) This chapter provides a brave attempt to dispute a priori assumptions about the relationship between old age and cognitive decline and deterioration. The authors argue for a sensory decline, rather than "the usual suspect" of cognitive decline, as a barrier to adequate performance on neuropsychological tests. Moreover, another major obstacle faced by older adults who encounter neuropsychological assessments is the threatening and unfamiliar testing situation, which often puts them at a disadvantage compared with younger adults. Self-fulfilling prophecies and the internalization of negative stigma regarding the relationship between old age and cognitive impairments are also substantial obstacles to adequate performance of older adults on neuropsychological tests.

These highly diverse chapters have several aspects in common. First, they address multiple levels of manifestations of ageism. All of the chapters in this section show that ageism is manifested in social interactions involving older adults (see, for example, Kydd et al. 2018). Moreover, ageism is well-internalized and impacts older adults through their belief systems and expectations, influencing social integration 
and their relations to other people (Shiovitz-Ezra et al. 2018; Gewirtz-Meydan et al. 2018). Ageism is also present at the meso-level, and manifests in interactions with professionals (Wyman, Shiovitz-Ezra, and Bengel 2018; Bodner et al. 2018; BenDavid et al. 2018). These may include a variety of health or mental health care professionals (Wyman, Shiovitz-Ezra, and Bengel 2018; Fialová et al. 2018; Bodner et al. 2018; Evans, Ben-David et al. 2018) or long-term care workers (GewirtzMeydan et al. 2018). Finally, ageism also occurs at the macro-level, as clearly illustrated in policies which discriminate against older immigrants (Dolberg, Sigurðardóttir, and Trummer 2018), older adults with dementia (Evans), or older adults with other health conditions (Wyman, Shiovitz-Ezra, and Bengel 2018).

Another common feature of these chapters is the emphasis on multiple jeopardies that older adults experience. The chapters demonstrate that ageism increases vulnerability in old age, which is often further amplified by impaired health status (Gewirtz-Meydan et al. 2018; Wyman, Shiovitz-Ezra, and Bengel 2018; Fialová et al. 2018), immigration status (Dolberg, Sigurðardóttir, and Trummer 2018), mental illness (Bodner et al. 2018), dementia status (Evans), or a sensory decline (BenDavid et al. 2018). These multiple vulnerabilities correspond with the chapter by Krekula et al. (2018; Chap. 3) in the previous section, and support the need to view ageism in context, as part of other potential sources of discrimination. Healthism, disablism, lookism, and sexism represent discrimination based on qualities other than age. The ten chapters presented in this section clearly demonstrate the interaction of ageism with these other bases for discrimination. Hence, it is often not age per se, but age in combination with other qualities that promotes discrimination.

One question raised by this section is "What would be considered a non-ageist approach?" The chapter on ageism in the visual media by Loos and Ivan (2018; Chap. 11) attempts to answer this question by arguing for the importance of diversity in older adults' representations and experiences. They support a transition from the portrayal of older adults in the visual media as invisible, weak, or frail to other, more nuanced portrayals of ageing and old age. However, they argue that the current successful ageing and active ageing models do not fit the ageing process of all older adults, and, thus, they must be diversified. This is similar to the arguments made by Gewirtz-Meydan et al. (2018) in this section regarding sexuality in the age of Viagra. Providing older adults with diverse models of ageing is a necessary next step in creating a non-ageist society. This claim is also supported in the previous section by Lev et al., who see a long continuum that includes impairment, failure, and disability as well as successful or active ageing, which should be acknowledged and respected. The chapters by Wyman, Shiovitz-Ezra, and Bengel (2018) and Fialová et al. (2018) in this section, on the other hand, argue that a non-ageist approach must be individually tailored. Although age can be one characteristic to take into account in medical diagnosis or treatment, it is by no means the only criterion. An individualized approach to care takes into account a variety of factors, not just chronological age. Such an approach is non-ageist and highly appropriate for both young and old.

Other chapters, such as the chapter by Bodner et al. (2018; Chap. 15) on ageism in the mental health system, the chapter by Evans (2018; Chap. 16) on ageism and dementia, and the chapter by Ben-David et al. (2018; Chap. 17) on ageism and neuropsychological assessment, argue for increased knowledge and awareness as a 
means to address ageism. These authors, as well as others in this section, demonstrate the role of the beliefs and attitudes of health and mental health professionals in shaping reality. Greater awareness of ageist attitudes can help overcome some of the ageist practices currently in use.

This section on the manifestations and consequences of ageism is important because it demonstrates the pervasiveness of ageism and its negative contribution to the life and care of older adults. Ageism can be subtle and hardly noticed or explicit and well-acknowledged. Regardless of its form, it shapes the views of older adults about their abilities and needs as well as the views of the people surrounding them. Although the chapters do not aim to provide solutions to combat ageism, they do point to future directions which could improve the wellbeing and quality of life of older adults. These can be at the policy level (detailed in the next section), as well as at the individual level, for example in the form of educational interventions to promote individualized approaches and increase awareness of ageist attitudes.

\section{References}

Ben-David, B. M., Malkin, G., \& Erel, H. (2018). Ageism and neuropsychological tests. In L. Ayalon \& C. Tesch-Römer (Eds.), Contemporary perspectives on ageism: Vol. 19. International perspectives on aging (pp. 277-297). Berlin: Springer.

Bodner, E., Palgi, Y., \& Wyman, F. (2018). Ageism in mental health assessment and treatment of older adults. In L. Ayalon \& C. Tesch-Römer (Eds.), Contemporary perspectives on ageism: Vol. 19. International perspectives on aging (pp. 241-262). Berlin: Springer.

Dolberg, P. H., Sigurðardóttir, S., \& Trummer, U. (2018). Ageism and older immigrants. In L. Ayalon \& C. Tesch-Römer (Eds.), Contemporary perspectives on ageism: Vol. 19. International perspectives on aging (pp. 177-191). Berlin, Germany: Springer.

Evans, S. C. (2018). Ageism and dementia. In L. Ayalon \& C. Tesch-Römer (Eds.), Contemporary perspectives on ageism: Vol. 19. International perspectives on aging (pp. 263-275). Berlin: Springer.

Fialová, D., Kummer, I., Držaić, M., \& Leppee, M. (2018). Ageism in medication use in older patients. In L. Ayalon \& C. Tesch-Römer (Eds.), Contemporary perspectives on ageism: Vol. 19. International perspectives on aging (pp. 214-240). Berlin: Springer.

Gewirtz-Meydan, A., Hafford-Letchfield, T., Benyamini, Y., Phelan, A., Jackson, J., \& Ayalon, L. (2018). Ageism and sexuality. In L. Ayalon \& C. Tesch-Römer (Eds.), Contemporary perspectives on ageism: Vol. 19. International perspectives on aging (pp. 149-162). Berlin: Springer.

Krekula, C., Nikander, P., \& Wilińska, M. (2018). Multiple marginalizations based on age: gendered ageism and beyond. In L. Ayalon \& C. Tesch-Römer (Eds.), Contemporary perspectives on ageism: Vol. 19. International perspectives on aging (pp. 33-50). Berlin: Springer.

Kydd, A., Fleming, A., Gardner, S., \& Hafford-Letchfield, P. (2018). Ageism in the third age. In L. Ayalon \& C. Tesch-Römer (Eds.), Contemporary perspectives on ageism: Vol. 19. International perspectives on aging (pp. 115-130). Berlin: Springer.

Hardwig, J. (1997). Is there a duty to die? Hastings Center Report, 27(2), 34-42.

Levy, B. R. (2001). Eradication of ageism requires addressing the enemy within. The Gerontologist, $41(5), 578-579$.

Liang, J., \& Luo, B. (2012). Toward a discourse shift in social gerontology: From successful aging to harmonious aging. Journal of Aging Studies, 26(3), 327-334. 
Loos, E., \& Ivan, L. (2018). Visual ageism in the media. In L. Ayalon \& C. Tesch-Römer (Eds.), Contemporary perspectives on ageism: Vol. 19. International perspectives on aging (pp. 163176). Berlin: Springer.

Shiovitz-Ezra, S., Shemesh, J., Gardner, S., \& McDonnell- Naughton, M. (2018). Pathways from ageism to loneliness. In L. Ayalon \& C. Tesch- Römer (Eds.), Contemporary perspectives on ageism: Vol. 19. International perspectives on aging (pp. 131-147). Berlin: Springer.

Wyman, M. F., Shiovitz-Ezra, S., \& Bengel, J. (2018). Ageism in the health care system: Providers, patients, and systems. In L. Ayalon \& C. Tesch-Römer (Eds.), Contemporary perspectives on ageism: Vol. 19. International perspectives on aging (pp. 193-213). Berlin: Springer.

Open Access This chapter is licensed under the terms of the Creative Commons Attribution 4.0 International License (http://creativecommons.org/licenses/by/4.0/), which permits use, sharing, adaptation, distribution and reproduction in any medium or format, as long as you give appropriate credit to the original author(s) and the source, provide a link to the Creative Commons license and indicate if changes were made.

The images or other third party material in this chapter are included in the chapter's Creative Commons license, unless indicated otherwise in a credit line to the material. If material is not included in the chapter's Creative Commons license and your intended use is not permitted by statutory regulation or exceeds the permitted use, you will need to obtain permission directly from the copyright holder.

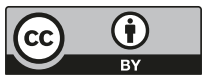

